\title{
SELECTED ANTECEDENTS OF THE IMPORTANCE OF NUTRITION CLAIMS FOR FOOD PROCESSORS AND DISTRIBUTORS
}

\author{
Paweł Bryła ${ }^{\bowtie}$ \\ University of Lodz, Poland
}

\begin{abstract}
The purpose of this paper is to examine the importance attached to nutrition claims placed on food packaging from the perspective of Polish food processors and distributors. A total of 78 completed questionnaires were obtained with the use of the CAWI methodology. The author used correlations, t-statistics, ANOVAs, and simple and multiple regression analyses. In simple regressions, 6 independent variables turned out to influence the declared importance of nutrition claims in a statistically significant way: 1) perceived credibility of nutrition claims; 2) agreeing that the availability of health-related information is not sufficient for the vast majority of Polish consumers to change their preferences for the choice of foods; 3 ) strong belief that food products carry too many nutrition claims; 4) self-reported knowledge about the healthiness of one's diet; 5) respondent age; and 6) seniority of the respondent in the companies surveyed. In a multiple regression model, only variables 1,2 , and 3 remained statistically significant at $p<0.05$. An increase in the perceived credibility and stronger agreement with the above statement increase the importance attached to nutrition claims, whereas believing that foods carry an excessive number of nutrition claims reduces it.
\end{abstract}

Keywords: nutrition claims; health-related information; food processors; food distributors; labeling

\section{INTRODUCTION}

Credence attributes clearly play an increasingly important role in food marketing and consumer behavior.
Labels and information signaling credence are important in consumer decision-making. Seven main categories of credence characteristics can be identified in the literature (Fernqvist and Ekelund, 2014): (a) health; (b) organic food (Bryła, 2013; 2016; 2018); (c) origin (Bryła, 2015; 2017); (d) brand; (e) production methods; (f) ethics; and (g) descriptive food names and ingredients. Confidence in credence attributes leads to brand loyalty (Lassoued and Hobbs, 2015). It is crucial to understand the role that firms, NGOs or government regulatory agencies, acting either independently or jointly as experts, play on the market of products with credence attributes (Sheldon, 2017).

There are more and more food products with increased or reduced levels of specific ingredients (e.g. extra calcium) that bring particular health benefits (e.g. stronger bones) (Van Trijp and Van Der Lans, 2007). These increased or reduced levels of certain ingredients are communicated via nutrition claims, and the health benefits derived from the presence or absence of such ingredients are communicated through health claims. While nutrition claims have been studied extensively from a consumer perspective, there is a lack of studies about the attitudes of food processors and distributors in this field.

The literature on the subject provides a mixed account of the effects of nutrition claims on consumer behavior. For instance, in northern Italy, the behavior of consumers concerned about nutrition claims was

$\bowtie$ Paweł Bryła, PhD Hab., Prof. UŁ, Department of International Marketing and Retailing, University of Lodz, Narutowicza 59a St., 90-131, Łódź, Poland, e-mail: pawel.bryla@uni.lodz.pl, http://orcid.org/0000-0003-1535-5659 
significantly linked to attributes influencing purchasing behavior, such as price, brand, and certification (Stranieri et al., 2010). Conversely, in the US, claims did not affect product evaluations or purchase intentions (Keller et al., 1997), and there was a weak effect of inclusion of a health claim on disease risk perceptions (Garretson and Burton, 2000). However, according to a later study conducted in the US, when favorable nutrition information or health claims are presented, consumers adopt more favorable attitudes toward the product, nutritional value, and purchase intentions (Kozup et al., 2003). Spanish results indicate that when consumers use nutrition information (either the fact panel or the claim label), it influences their choices of healthier food products (Barreiro-Hurlé et al., 2010). Using a large-scale quasi-experiment and panel data across eight product categories for more than 535,000 members of a grocery chain's frequent shopper program, Nikolova and Inman (2015) demonstrated that the point-of-sale nutrition scoring system helped consumers make healthier food choices, such that they switched to higher-scoring products in the post-rollout period. A meta-analysis suggests that nutrition labeling may be an effective approach to empowering consumers in choosing healthier products (Cecchini and Warin, 2016). Nevertheless, information may not always be effective in improving food choices. One explanation is that nutrition information is complex and difficult to convey in a clear, actionable manner. Furthermore, knowledge, while necessary, may not be sufficient to motivate behavior change. Even when consumers understand nutrition information, competing preferences for tastier, less expensive, or more convenient foods may lead them to make other choices (Guthrie et al., 2015).

Various kinds of information placed on food labels attract different levels of consumer attention. In a nationally representative sample of US adults, $61.6 \%$ of participants reported using the Nutrition Facts panel, $51.6 \%$ looked at the list of ingredients, $47.2 \%$ looked at serving size, and $43.8 \%$ reviewed health claims at least sometimes when deciding to purchase a food product (Ollberding et al., 2011). In south-eastern Poland, when choosing food, the consumers checked, in the first place, the expiration date ( $93.7 \%$ of the responses), followed by: price (63.6\%), and list of ingredients (62.2\%) (Niewczas, 2013). Another study conducted in Poland indicated that consumers primarily take into consideration the following information while purchasing food: price $(37.0 \%)$, use-by or best-before date $(26.0 \%)$, and the brand (25.6\%) (Krasnowska and Salejda, 2011).

The use of nutrition information is affected by geographic, psychographic and socio-demographic variables. Reading food labels is affected by diverse factors, associated with both the product and the consumer (or the circumstances of purchasing food). Purchasing a product for the first time gives a strong impulse to memorize the label (Ozimek and Tomaszewska-Pielacha, 2011). In the UK, the use of nutrition information is mainly driven by the interest in healthy eating, whereas whether an individual understands nutrition information on food labels mainly depends on his/her nutrition knowledge. Both are in turn affected by demographic variables, but in different ways (Grunert et al., 2010b). A six-country study (conducted in the UK, Sweden, France, Germany, Poland, and Hungary) showed that information on calories, fat and sugar is most often looked for. In addition to national particularities, the use and understanding of nutrition information on food labels is also affected by differences in interest in healthy eating and in nutrition knowledge, and by social grade (Grunert et al., 2010a). In Malaysia, females, young adults aged between 18 and 30 years, tertiary-educated, singles, employed individuals, physically active adults and non-smokers were significantly more likely to use nutrition labels (Cheah et al., 2015). Dörnyei and Gyulavári (2016) proposed a framework for label information search, consisting of three groups of personal factors that serve as antecedents: general personal factors (e.g. health consciousness and socio-demographics), label-related personal factors (e.g. label-related self-efficacy, trust in labels and the perceived usefulness of labels) and product category-related personal factors (trust in food products, enduring involvement, experience and perceived quality differences).

\section{MATERIAL AND METHODS}

In the framework of a research project on the role of health-related information in the marketing and consumption of food products, funded by the National Science Center under an OPUS grant No. 2015/17/B/ HS4/00253, a survey was carried out with Polish food processors and distributors. The respondents' contact data was retrieved from several databases, in particular Polish Telephone Directories (www.pkt.pl; categories: "Food products-production, wholesale" and 
"Food articles-retailing"), the Webazy database of Polish economic operators (categories related to processing and trade in food products), a database of Polish exporters (www.poland-export.pl; category: "Food articles and beverages"), a database of participants of trade fairs: Polagra Food 2017 and Natura Food 2017, and databases of organic processors and traditional food producers registered by the Polish Ministry of Agriculture and Rural Development. The survey was prepared using a professional Web service (profitest.pl), with the link being e-mailed to the respondents. The survey was intended to cover all food production and distribution companies whose e-mail addresses could be found in the aforementioned databases. As regards Polish Telephone Directories, the companies had to be filtered in order to remove the operators who fail to meet the defined criteria (e.g. providers of equipment and services for the food industry) from the sample. The survey was conducted in February and March 2018, and was preceded by a pilot study. At the beginning of the survey, the respondents were informed about the meaning of health claims and nutrition claims, with some examples of each type provided.

The sample consisted of respondents from $78 \mathrm{com}-$ panies. The predominant field of activity for $50 \mathrm{com}$ panies surveyed was food processing and production; and for 26 companies, it was food distribution, in particular wholesale; 2 respondents declared to be focused on other activities. The companies were located in all Polish regions (voivodeships) except for Opolskie and Świętokrzyskie. 22 respondents were located in the Mazowieckie voivodeship, with Warsaw as the capital city. The companies differed quite strongly in size. The mean number of employees was 214 with a median of 25.5; the third quartile amounted to 70 . Therefore, small- and medium-sized enterprises dominated the sample. When it comes to distribution by industry, the largest groups of companies surveyed are active in the general grocery (18), fruit and vegetables (15), meat (11), and bakery and confectionary (10) industries. While the survey was distributed to managers of the companies concerned, they could delegate the filling-in to other competent professionals employed in their companies. As a result, the questionnaire was completed by 30 managing owners, 8 CEOs, 8 other executives (e.g. chief marketing officers), 19 specialists and 4 other professionals appointed by the managers. The survey was answered by 34 women and 44 men, and was based on the CAWI
(Computer Assisted Web Interview) methodology. The author used correlation tests, t-statistics, ANOVAs, and simple and multiple regression analyses to explore the results. The analyses were conducted in MS Excel 2013 and Statistica 12.0.

\section{RESULTS AND DISCUSSION}

The respondents were asked to evaluate the importance of selected information placed on food packaging (Table 1). It turned out that in the opinion of food processors and distributors, the list of ingredients is the most important type of information on the label, followed by expiry date and country of origin. These three types of information are relatively objective and usually not susceptible to manipulation. Nutrition claims ranked quite high (fourth), just above quality signs and health claims. Price ranked $7^{\text {th }}$ on the list of critical information types. It may be related to the fact that price is often added to the label at later stages of the distribution channel. While the manufacturer may put a recommended price

Table 1. Evaluation of the importance of selected types of information on food product packaging

\begin{tabular}{lcc}
\hline \multirow{2}{*}{ Information type } & \multicolumn{2}{c}{ Information importance } \\
\cline { 2 - 3 } & value (1-5) & rank \\
\hline List of ingredients & 4.654 & 1 \\
Expiry date & 4.577 & 2 \\
Country of origin & 4.090 & 3 \\
Nutrition claims & 3.897 & 4 \\
Quality signs & 3.833 & 5 \\
Health claims & 3.628 & 6 \\
Price & 3.526 & 7 \\
Organic certificate & 3.513 & 8 \\
Brand & 3.128 & 9 \\
Recommendations of scientific & 2.808 & 10 \\
institutes & & 11 \\
Cooking recipes & 2.179 & \\
\hline
\end{tabular}

Note: the importance of information types was evaluated using 5 answer options (crucial, rather big, average, rather small, with no importance) which subsequently were attributed the following values: $5,4,3,2,1$, respectively.

Source: own research 
Table 2. Evaluation of importance of selected types of nutritional information on food product packaging

\begin{tabular}{lcc}
\hline \multirow{2}{*}{\multicolumn{1}{c}{ Information type }} & \multicolumn{2}{c}{ Information importance } \\
\cline { 2 - 3 } & value (1-5) & rank \\
\hline Content of sugar & 4.179 & 1 \\
Content of fat & 3.885 & 2 \\
Content of salt & 3.782 & 3 \\
Energy value (calories) & 3.718 & 4 \\
Content of Omega-3 fatty acids & 3.667 & 5 \\
Content of protein & 3.615 & 6 \\
Content of vitamins & 3.500 & 7 \\
\hline
\end{tabular}

Note: as in Table 1.

Source: own research.

on the product, it is not necessary. In fact, it is usually the retailer that decides about the consumer price and sticks the price label to the packaging or shelf. The organic certificate and brand ranked even lower. The relatively low importance of brands is surprising. The development of strong brands may constitute a powerful marketing tool to make a product stand out in the market. Hence, the importance of brand seems to be underestimated by Polish food processors and distributors. For the processors and distributors, the least important information types are: recommendation of a scientific institute; and cooking recipe.

As far as nutritional information is concerned, the most important information types are the content of sugars, followed by the content of fats, and the content of salt (Table 2). It seems that the processors and distributors place the strongest emphasis on information on the contents of those ingredients which, if consumed in excessive amounts, are recognized as a risk factor of dietary diseases. Energy value expressed in calories was ranked fourth. Information about beneficial nutrients, such as Omega-3 fatty acids, proteins and vitamins, was found to be relatively less important. This may suggest that prevention orientation (emphasizing the avoidance of negative consequences) prevails over promotion orientation (taking advantage of positive effects).

A number of analyses were conducted in order to identify the variables correlating with the importance attached to nutrition claims on the food packaging. Table 3 presents selected Pearson correlations $(r)$ and their statistical significance $(p)$. It turned out that the

Table 3. Pearson correlation coefficients between the assessed importance levels of nutrition claims and selected variables

\begin{tabular}{lcc}
\hline \multicolumn{1}{c}{ Variable } & $r$ & $p$ \\
\hline Understandability of nutrition claims & 0.031 & 0.788 \\
Credibility of nutrition claims & $\mathbf{0 . 4 1 8}$ & $\mathbf{0 . 0 0 1}$ \\
Agreeing that the availability of health-related information is not sufficient for the vast & $\mathbf{0 . 4 2 3}$ & $<\mathbf{0 . 0 0 1}$ \\
majority of Polish consumers to change their preferences for the choice of foods & & 0.176 \\
Agreeing that an important segment of consumers exist who pay attention to health claims & & 0.123 \\
and nutrition claims & 0.060 & 0.603 \\
Agreeing that the use of unreliable health claims is a serious problem in Poland & 0.147 & 0.200 \\
Agreeing that the use of unreliable nutrition claims is a serious problem in Poland & -0.199 & 0.081 \\
Share of products with health claims in the company's product range & 0.108 \\
Share of products with nutrition claims in the company's product range & 0.129 \\
Number of company employees & 0.077 & 0.348 \\
Company age & $\mathbf{- 0 . 3 7 0}$ & 0.261 \\
Respondent age & $\mathbf{0 . 3 0 3}$ & 0.502 \\
Respondent seniority & -0.564 & $\mathbf{0 . 0 0 1}$ \\
Self-reported healthiness of one's diet & $\mathbf{0 . 0 0 7}$ \\
Self-reported knowledge about a healthy diet & 0.624 & $\mathbf{0 . 0 2 9}$
\end{tabular}

Source: own research. 
importance of nutrition claims is positively associated with their credibility; with the respondents' self-reported knowledge about healthy diets; and with opinions on the effectiveness of health-related information. Agreeing that the availability of health-related information is not sufficient for the vast majority of Polish consumers to change their preferences for the choice of foods somewhat paradoxically increases the perceived importance of nutrition claims. This information seems not to be a sufficient condition for changing the dietary patterns, albeit a necessary one, at least in the opinion of the processors and distributors surveyed. Furthermore, the declared importance of nutrition claims is negatively correlated with the respondents' age and seniority in the companies under study. Therefore, older and more experienced managers tend to attach less importance to the nutrition claims. It may be related to their skepticism toward the reliability of nutrition claims, but also to a greater sensitivity of older respondents to other types of information placed on food labels.

The evaluation of the importance of nutrition claims by food processors and distributors is related to how they assess the amount of this kind of information (Table 4). Those who think these claims are too scarce find it more important than those who consider their presence to be sufficient. Those respondents who believe product labels include excessive amounts of nutrition claims find it much less important. That pattern was also observed for health claims but was not statistically significant in relation to the declared importance of nutrition claims. An analogous analysis of the declared importance of health claims showed a significant variance on the basis of the evaluation of the quantity of health claims, and not nutrition claims.

Additional analyses showed that the importance of nutrition claims does not depend on whether the respondent's company is or is not active in e-commerce $(t=0.829, p=0.410)$. It is not related to whether the company offers dietary supplements $(t=0.770, p=0.444)$, organic food $(t=1.156, p=0.251)$, functional food $(t=0.767, p=0.445)$ or fair trade products $(t=0.445$, $p=0.658)$. Moreover, it does not vary in function of the location of the companies surveyed, as far as the size of the city is concerned $(F=0.003, p=1.000)$. It is also independent of the company's field of specialization $(F=1.405, p=0.210)$. Neither does it depend on the respondent's gender $(t=1.392, p=0.168)$, education level $(F=0.241, p=0.786)$ or position in the company $(F=1.786, p=0.141)$.

Following these preliminary tests of factors potentially influencing the declared importance of nutrition claims, the author performed simple regression analyses for variables statistically significant in $t$ tests, Pearson's correlation tests and ANOVAs. Six independent variables turned out to be statistically significant predictors of the importance of nutrition claims in one-factor regression models: 1) perceived credibility of nutrition claims $(\beta=0.418, \mathrm{SE}=0.104, t=4.012, p<0.001$, $\left.\mathrm{R}^{2}=0.175\right), 2$ ) agreeing that the availability of healthrelated information is not sufficient for the vast majority of Polish consumers to change their previous preferences for the choice of foods $(\beta=0.423, \mathrm{SE}=0.104$,

Table 4. Evaluation of the importance of nutrition and health claims depending on the assessment of the amount of selected types of information on food product packaging (ANOVA)

\begin{tabular}{lccccc}
\hline \multirow{2}{*}{ Information type } & \multicolumn{5}{c}{ Amount of information } \\
\cline { 2 - 6 } & Too much & Appropriate & Too little & $F$ & $p$ \\
\hline Importance of nutrition claims & & & & \\
Health claims & 3.688 & 3.875 & 4.091 & 0.942 & 0.394 \\
Nutrition claims & 3.267 & 4.000 & 4.200 & $\mathbf{5 . 3 1 7}$ & $\mathbf{0 . 0 0 7}$ \\
Importance of health claims & & & & \\
Health claims & 3.125 & 3.650 & 3.955 & $\mathbf{3 . 3 4 9}$ & $\mathbf{0 . 0 4 0}$ \\
Nutrition claims & 3.200 & 3.625 & 4.067 & 2.911 & 0.061 \\
\hline
\end{tabular}

Source: own research. 
Table 5. Selected predictors of the importance attached to nutrition claims (multiple regression model)

\begin{tabular}{lcccc}
\hline Independent variables & $\beta$ & $\mathrm{SE}$ & $t(72)$ & $p$ \\
\hline Quantity $^{\mathrm{a}}$ & -0.202 & 0.101 & -2.007 & 0.048 \\
Credibility $^{\mathrm{b}}$ & 0.287 & 0.102 & 2.822 & 0.006 \\
Effectiveness $^{\mathrm{c}}$ & 0.329 & 0.098 & 3.352 & 0.001 \\
\hline
\end{tabular}

Notes: a) too much nutrition claims, b) of nutrition claims, c) agreeing that the availability of health-related information is not sufficient for the vast majority of Polish consumers to change their preferences for the choice of foods

Source: own research.

$\left.\left.t=4.072, p<0.001, \mathrm{R}^{2}=0.179\right), 3\right)$ belief that food products carry too many nutrition claims $(\beta=-0.342$, $\left.\left.\mathrm{SE}=0.108, t=-3.174, p<0.002, \mathrm{R}^{2}=0.117\right), 4\right)$ selfreported knowledge about the healthiness of one's diet $\left(\beta=0.247, \mathrm{SE}=0.111, t=2.227, p=0.029, \mathrm{R}^{2}=0.061\right)$, 5 ) respondent age $(\beta=-0.370, \mathrm{SE}=0.107, t=-3.471$, $\left.p<0.001, \mathrm{R}^{2}=0.137\right)$, and 6) seniority of respondents in the companies surveyed $(\beta=-0.303, \mathrm{SE}=0.109$, $\left.t=-2.771, p=0.007, \mathrm{R}^{2}=0.092\right)$.

Independent variables that affected the declared importance of nutrition claims in a statistically significant way in simple regression models were subsequently included in the multiple regression model. Those that failed to reach the $p<0.05$ significance level were gradually eliminated from the model in order to achieve the smallest possible number of variables. As a result of this procedure, a model with only three independent variables was formulated (Table 5). The model explains $32.8 \%$ of variance in the dependent variable and is statistically highly significant $(p<0.0001)$. In the multiple regression model, the declared importance of nutrition claims among food processors and distributors surveyed increases in line with how much they value the credibility of such claims and with how strongly they agree that these claims are effective ("the availability of healthrelated information is not sufficient for the vast majority of Polish consumers to change their preferences for the choice of foods"). Conversely, it decreases as the respondents' belief that food products carry too many nutrition claims grows stronger. Paradoxically, being realistic about the effectiveness of nutrition claims raises their declared importance. As mentioned above, this may be because nutrition claims are considered to be a necessary (though insufficient) condition for dietary modifications. However, this explanation needs empirical verification.

\section{CONCLUSIONS}

Nutrition claims are credence attributes which grow in importance in the food market. The understanding, perception, use and effectiveness of nutrition claims has been examined in the literature of the subject from the perspective of consumer behavior. However, there is a lack of studies on the attitude towards, and evaluation of, nutrition claims among other key actors of the food supply chain. The purpose of this paper is to fill in the literature gap by focusing on Polish processors' and retailers' opinions on nutrition claims found on food packaging. The sample consisted of managers and professionals representing 78 companies, mostly food processors. They evaluated the importance of selected types of information placed on food products. Nutrition claims ranked relatively high (fourth), following only the list of ingredients, expiry date, and country of origin. Among nutrition claims themselves, the highest importance was attached to prevention-focused messages on the contents of sugars, fats, salt and calories. A series of statistical analyses, including t tests, Pearson's correlation tests, and ANOVAs were conducted in order to identify potential predictors of the importance attached to nutrition claims.

Six antecedents turned out to be statistically significant in simple regressions models: 1) perceived credibility of nutrition claims; 2) agreeing that the availability of health-related information is not sufficient for the vast majority of Polish consumers to change their preferences for the choice of foods; 3 ) strong belief that food products carry too many nutrition claims; 4) selfreported knowledge about the healthiness of one's diet; 5) respondent age; and 6) seniority of respondents in the companies surveyed. Combining them into a multiple regression model led to a reduction in the number of statistically significant independent variables, with only the first three listed above being retained.

The limitations of this research include a small sample size and a group of respondents which are heterogeneous in terms of positions they hold in the companies surveyed. The respondents' knowledge about the use of health claims and nutrition claims in their companies may also be sometimes limited. 
Further research may focus on particular types of nutrition claims used in a given sector of the food industry. A comparison of the perspectives of producers, distributors and consumers would also be helpful in getting a better understanding of the aspects considered.

\section{SOURCE OF FINANCING}

Our research study was funded by the National Science Centre within an Opus research grant no. 2015/17/B/ HS4/00253.

\section{REFERENCES}

Barreiro-Hurlé, J., Gracia, A., de-Magistris, T. (2010). Does nutrition information on food products lead to healthier food choices. Food Pol., 35(3), 221-229. Retrieved from: https://doi.org/10.1016/j.foodpol.2009.12.006.

Bryła, P. (2013). Marketing ekologicznych produktów żywnościowych - wyniki badania wśród polskich przetwórców [Marketing of Ecological Food Products - Results of a Research Study Among Polish Processors]. Rocz. Ochr. Środ., 15, 2899-2910.

Bryła, P. (2015). The role of appeals to tradition in origin food marketing. A survey among Polish consumers. Appetite, 91, 302-310. Retrieved from: https://doi.org/10.1016/j.appet. 2015.04.056.

Bryła, P. (2016). Organic food consumption in Poland: Motives and barriers. Appetite, 105, 737-746. Retrieved from: https://doi.org/10.1016/j.appet.2016.07.012.

Bryła, P. (2017). The perception of EU quality signs for origin and organic food products among Polish consumers. Qual. Ass. Saf. Crops Foods, 9(3), 345-355. Retrieved from: https://doi.org/10.3920/QAS2016.1038.

Bryła, P. (2018). Organic food online shopping in Poland. Brit. Food J., 120(5), 1015-1027. Retrieved from: https:// doi.org/10.1108/BFJ-09-2017-0517.

Cecchini, M., Warin, L. (2016). Impact of food labelling systems on food choices and eating behaviours: a systematic review and meta-analysis of randomized studies. Obes. Rev, 17(3), 201-210. Retrieved from: https://doi. org/10.1111/obr.12364.

Cheah, Y., Moy, F., Loh, D. (2015). Socio-demographic and lifestyle factors associated with nutrition label use among Malaysian adults. Brit. Food J., 117(11), 2777-2787. Retrieved from: https://doi.org/10.1108/BFJ-01-2015-0001.

Dörnyei, K., Gyulavári, T. (2016). Why do not you read the label? - an integrated framework of consumer label information search. Int. J. Cons. Stud., 40(1), 92-100. Retrieved from: https://doi.org/10.1111/ijcs.12218.
Fernqvist, F., Ekelund, L. (2014). Credence and the effect on consumer liking of food - A review. Food Qual Pref, 32(C), 340-353. Retrieved from: https://doi.org/10.1016/j. foodqual.2013.10.005.

Garretson, J., Burton, S. (2000). Effects of Nutrition Facts Panel Values, Nutrition Claims, and Health Claims on Consumer Attitudes, Perceptions of Disease-Related Risks, and Trust. JPP\&M, 19(2), 213-227. Retrieved from: https://doi.org/10.1509/jppm.19.2.213.17133.

Grunert, K., Fernández-Calemín, L., Wills, J., Storcksdieck, S., Nureeva, L. (2010a). Use and understanding of nutrition information on food labels in six European countries. J Pub Health, 18(3), 261-277. Retrieved from: https://doi. org/10.1007/s10389-009-0307-0.

Grunert, K., Wills, J., Fernández-Celemín, L. (2010b). Nutrition knowledge, and use and understanding of nutrition information on food labels among consumers in the UK. Appetite, 55(2), 177-189. Retrieved from: https://doi.org/ 10.1016/j.appet.2010.05.045.

Guthrie, J., Mancino, L., Lin, C. (2015). Nudging Consumers toward Better Food Choices: Policy Approaches to Changing Food Consumption Behaviors. Psych. Mark., 32(5), 501-511. Retrieved from: https://doi.org/10.1002/ mar.20795.

Keller, S., Landry, M., Olson, J., Velliquette, A., Burton, S., Andrews, J. (1997). The effects of nutrition package claims, nutrition facts panels, and motivation to process nutrition information on consumer product evaluations. JPP\&M, 16(2), 256-269.

Kozup, J., Creyer, E., Burton, S. (2003). Making Healthful Food Choices: The Influence of Health Claims and Nutrition Information on Consumers' Evaluations of Packaged Food Products and Restaurant Menu Items. J. Mark., 67(2), 19-34. Retrieved from: https://doi.org/10.1509/jmkg.67. 2.19.18608.

Krasnowska, G., Salejda, A. (2011). Ocena wiedzy konsumentów na temat znakowania żywności [Consumer knowledge about food product labelling]. Żywn. Nauka Technol. Jakość, 1(74), 173-189.

Lassoued, R., Hobbs, J. (2015). Consumer confidence in credence attributes: The role of brand trust. Food Pol., 52, 99-107. Retrieved from: https://doi.org/10.1016/j.foodpol. 2014.12.003.

Niewczas, M. (2013). Kryteria wyboru żywności [Food choice criteria]. Żywn. Nauka Technol. Jakość, 6(91), 204-219.

Nikolova, H., Inman, J. (2015). Healthy Choice: The Effect of Simplified Point-of-Sale Nutritional Information on Consumer Food Choice Behavior. J. Mark. Res., 52(6), 817835. Retrieved from: https://doi.org/10.1509/jmr.13.0270.

Ollberding, N., Wolf, R., Contento, I. (2011). Food Label Use and Its Relation to Dietary Intake among US Adults. 
Bryła, P. (2019). Selected antecedents of the importance of nutrition claims for food processors and distributors. J. Agribus. Rural Dev., 2(52), 103-110. http://dx.doi.org/10.17306/J.JARD.2019.01117

J. Acad. Nutr. Diet, 111(5, Suppl.), S47-S51. Retrieved from: https://doi.org/10.1016/j.jada.2011.03.009.

Ozimek, I., Tomaszewska-Pielacha, M. (2011). Czynniki wpływające na czytanie przez konsumentów informacji zamieszczanych na opakowaniach produktów żywnościowych [Factors influencing consumer reading of information placed on food product packaging]. Stud. Mater. Pol. Stow. Zarz. Wiedz., 52, 26-35.

Sheldon, I. (2017). Certification Mechanisms for Credence Attributes of Foods: Does It Matter Who Provides Diagnosis?
An. Rev. Res. Econ., 9(1), 33-51. Retrieved from: https:// doi.org/10.1146/annurev-resource-100516-053630.

Stranieri, S., Baldi, L., Banterle, A. (2010). Do nutrition claims matter to consumers? An empirical analysis considering European requirement. JAE, 61(1), 15-33. Retrieved from: https://doi.org/10.1111/j.1477-9552.2009.00223.x.

Van Trijp, H., Van Der Lans, I. (2007). Consumer perceptions of nutrition and health claims. Appetite, 48(3), 305-324. Retrieved from: https://doi.org/10.1016/j.appet.2006.09. 011. 